\title{
Evaluation of decision making criteria with special reference to quantitative and qualitative paradigms
}

\author{
Okechukwu Itanyi ${ }^{1}$, Uzoma Jonathan F. Ewurum ${ }^{2}$ and Wilfred I. Ukpere ${ }^{3 *}$ \\ ${ }^{1}$ Nigerian Communication Commission, Abuja, Nigeria. \\ ${ }^{2}$ Department of Management, University of Nigeria, Enugu Campus, Nigeria. \\ ${ }^{3}$ Department of Industrial Psychology and People Management, Faculty of Management, University of Johannesburg, \\ South Africa.
}

Accepted 8 October, 2012

\begin{abstract}
A common problem these days in various organizations shows itself in excessive time spent dealing with short-term crises, namely 'putting out fires'. This problem usually results from a lack of long-range planning, and, typically, the absence of a strategic plan. Individual employees and the organization as a whole live from day to day, never knowing what to expect. This may result in a loss of organizational productivity and effectiveness. The objective of this paper is to establish the level at which managers utilise the quantitative and qualitative techniques as decision-making tools in organisations. In other words, the paper is aimed at establishing the level of the use of qualitative and quantitative method of data analysis in problem solving and decision-making, as well as analysing both techniques when used separately or jointly. Several literatures were consulted, which revealed that some decision-making were done either by qualitative or quantitative technique or by both. Most organizations today encounter problems due to paucity in the use of these techniques during planning. Therefore, top management of various organizations should equip themselves with the knowledge of both quantitative and qualitative techniques, in order to make well informed decisions for the development and growth of their organizations. The study proposed that a combination of both approaches is necessary owing to the wide range of data needed for organisational effectiveness. Contemporary and future-fit managers must possess the academic and experiential knowledge necessary to understand the methods and technologies that they manage.
\end{abstract}

Key words: Decision making, quantitative, qualitative, organisation.

\section{INTRODUCTION AND BACKGROUND OF THE STUDY}

During its evolution, administration has been acknowledged by practitioners and scientists as both an art and a science. As an art, it is considered that administration is informed by sensibilities, perceptions and intuitions. The administrator as an artist put in efforts to create new realities and influence others as he/she impacts the surrounding environment. As a science, administration is directed by an understanding of structure, schedules, systems and power. The administrator as a scientist collects and analyses information, assesses relationships, infers causality, generates and tests hypotheses

${ }^{*}$ Corresponding author. E-mail: wiukpere@uj.ac.za.
(Nisbett and Ross, 1980:1).

Trying to lead without art is in often problematic, while trying to lead without science is usually ineffective. Good administrators are probably both artists and scientists, who are able to integrate the two ways of thinking in the analysis of data (Birnbaum, 1988:7). Theory building in behavioural science (qualitative studies) integrated concepts and propositions from sociology, psychology, political science and economics, by providing an interdisciplinary framework that would later influence the behaviour of members of organizations (Gibson et al., 1991:10; Robbin and Jugde, 2009).

Quantitative analysis in management have been considered to have originated during the World War II period, when operations research teams were formed to 
deal with strategic and tactical problems faced by the military (Ukpere, 2010). These teams which often consisted of people with diverse specialties (e.g., engineers, mathematicians, and behavioural scientists) were joined together to solve common problems through the utilization of scientific methods (Anderson et al, 1994:2). After the war, many of these team members continued their research on quantitative approaches to decisionmaking, leading to the growth and use of management science in non-military applications such as healthcare, manufacturing, engineering projects, transport and traffic studies, communication, business and educational administration. Hence, decision-making became the heart of the management/administrative process (Mann, 1976:2).

Decision-making is an essential process in organizational effectiveness. It has been well-defined as making a choice amongst alternatives. It is almost related to all managerial functions. Within the manufacturing domain, effective decisions are meant to achieve zero defects. Currently, this focus has also been applied to the service sector in order to create zero defects. Decision-making is an organizational process that has a powerful effect on organizational goals (Prasad, 2004).

Another name for managers is decision-makers. To survive and lead today's highly competitive and demand driven market, pressure is on management to make economic decisions. One of the essential managerial skills is the ability to allocate and utilize resources appropriately in an effort to efficiently achieve the optimal performance. In some cases, such as small scale low complexity environment, decision based on intuition with minimal quantitative basis may be reasonably acceptable and practical in achieving the goal of an organization. However, for a large-scale system, both quantitative and qualitative (that is intuition, experience, common sense) analyses are required to make the most effective decisions (Agrawal et al., 2010: 200). The organizational decision-making process involves proper and efficient implementation of strategic plans and methods to achieve desired business objective (Ehlers and Lazenby, 2007).

Dunn (1994:5) posits that almost all organizational problems are interdependent, subjective, artificial and dynamic. Problems rarely may be separated into independent, discrete and, mutually exclusive parts; problems are really systems with theological (purposive) properties, such that the quality of the whole is different from the quantitative sum of the parts. If this reasoning is integrated into the decision-making process, then managers would be able to face problems encountered in their daily tasks by analysing multiple alternatives. Qualitative and quantitative analyses (behavioural and mathematical techniques) can provide diverse knowledge.

Qualitative analysis is based primarily on the manager's judgement and experience. It includes the manager's conceptual and interpersonal ability to utilise behavioural techniques in problem solving. Qualitative analysis is considered more of an art than science. If the manager has had little experience with non-routine problems, or if a problem is sufficiently complex, then a quantitative analysis might be essentially considered for the manager's ultimate decision-making.

Quantitative analysis concentrates on the facts, data or quantitative aspects associated with problems. A manager's educational and technical knowledge of quantitative procedures help to enhance the decision-making process. When utilising a quantitative approach, a manager will concentrate on mathematical expressions that describe objectives, constraints and other relation-ships that exist around the problem (Valero, 1997:10-11).

\section{Statement of the problem}

A common problem these days in various organizations shows itself in excessive time spent in dealing with shortterm crises, namely "putting out fires." This problem usually results from a lack of long-term planning, and typically, the absence of a strategic plan. Individual employees and the organization as a whole live from day to day, never knowing what to expect. This may result in loss of organizational productivity and effectiveness. Examples of these short-term crises abound. One of the most recent, concerns the security firm G4S which handled the security for the London Olympics. The firm had to hire employees without proper vetting and training in order to meet their target, but still failed to meet the required result. In other companies, lack of planning can produce other short-term crises. For instance, lack of planning can result in shortages of salespeople, which may force a company to hire new people and put them to work almost immediately, sometimes without adequate training. This, in turn, can contribute to short-term productivity problems due to inexperience of the new employees. Therefore, effective managers should be conversant with various managerial tools, and be able to take them into consideration as a prerequisite for their actions and expectations. The ability to deal effectively with other people and accomplish work through them will remain a fundamental ingredient in the management process. This is especially true where relatively complex problems are undertaken by managerial teams. Human relations skills are certainly necessary; however, they may not be sufficient in managing complex situations. Technical competence is vital for various tasks. Cost analysis is involved in such diverse areas as product costing, budgeting, purchasing, and insurance, planning, and determining the amount and types of remuneration for employees. The use of quantitative and qualitative methods in evaluating and planning of business related functions will certainly become ubiquitous to organizational success. Great ideas and hard work are vital. However, proper application of pertinent analytical tools can ensure that a company is successful within a 
competitive global environment.

\section{Objectives of the study}

This study will consider both quantitative and qualitative managerial tools as vital ingredients for sound and effective decision-making process. Decision-making as a matter of fact is psycho-technical. The psychological use of information incorporated into managerial decisionmaking style is often combined with the practical and technical existence of data. Thus, managers may enhance their decision-making capabilities by learning, understanding and using various managerial techniques. Therefore, the main objective of this paper is to examine the position of the manager and the extent to which managers utilise quantitative and qualitative techniques in executing management functions, in order to effectively improve their managerial decision-making processes. Other objectives of the paper are:

1. To evaluate the extent to which managers utilise quantitative and qualitative criteria in organizational decision-making.

2. To explicate the levels or functional areas where these managerial techniques might have real or potential applications.

3. To determine the level at which the tools may be used exclusively or in combination during managerial decisionmaking process.

\section{RESEARCH METHODOLOGY}

The research was based on an exploratory method. Exploratory studies are typically conducted to satisfy the researchers' curiosity and desire for better understanding; to test the feasibility of undertaking more extensive studies; to develop the method to be employed in any subsequent study; to explicate the central concepts and constructs of a study; to determine priority for future research; and to develop a new assumptions about an existing phenomenon. In their view, Selltiz et al. (1965 cited in Babbie et al., 2001) emphasize three methods by means of which exploratory research may be conducted, namely a review of related literatures; a survey of people who have particular experience of the problem to be studied; and an analysis of 'insight stimulating' examples. Exploratory studies usually lead to insight and comprehension rather than the collection of detailed, accurate and replicable data. Since this research intends to explore a wider phenomenon, it was reasonable to adopt the exploratory methods. It was necessary to follow open and flexible research strategies and to utilized methods such as detailed literature reviews, pertinent cases and expert views, which lead to insight and comprehension. Exploratory method was adopted because the paper is a non-empirical study. Being a non-empirical study, the research placed more emphasis on conceptual analysis and theory building. Theoretical literature on the qualitative and quantitative techniques as relevant tools for decision-making was analysed, and supported by the 'emic' perspective (authors' viewpoint).

\section{THEORETICAL FRAMEWORK}

Although most managers are used to managerial functions, only few do it efficiently. Majority of the managers have not been able to use minimum inputs to effectively produce optimal outputs that will bring satisfaction to their stakeholders. The reason is because most managers' role has merely been to balance and coordinate the interest of the organization members and work together within the limits set by the organization. Some managers recognize the politics within the organization and readily accept their roles as agents and arbitrators of conflicts.

Many managers have not realized that to increase management capability is to seek more rational and structured ways of making decisions and resolving problems. Thus, managers, in carrying out their managerial functions, should be well acquainted with the modern managerial techniques namely, quantitative and qualitative techniques of decision making. The manager should use the quantitative techniques to be explicit about the objectives of the organization, in order to identify and record the types of decision variables that will influence the objectives, identify and record pertinent interactions and trade-offs between decision variable, and record constraints on the values that the variable may assume.

The other technique employed by manager to solve problems is the qualitative technique, which has a humanizing effect on stakeholders. It should be mentioned at this juncture that brainstorming and nominal group techniques are qualitative tools for comprehensive planning and implementation. Included also in this approach is management by objectives, which minimises the subjective or personal prejudice elements since appraisal is based on agreed set objectives. This gives management better decisionmaking processes, because each manager discusses the goals and objectives of the organization with the subordinates. The technique is also participatory in nature because the managerial level is extended to incorporate the rank and file of employees. It is evident that these behavioural tools (owing to their artistic nature), require administrative and creative ability for successful application (Cainta, 2010:223).

Managers may enhance decision-making capabilities by learning more about quantitative methodologies and by better understanding their contributions to the decision-making process. A manager who is knowledgeable in quantitative decision-making procedures is in a much better position to compare and evaluate the qualitative and quantitative sources of information and, ultimately, to combine alternatives in making the best possible decisions.

Managers must recognize, adjust, react and accommodate many diverse behavioural situations which permeate the organization. Central to manager's problems are the many individuals and groups, including upper and middle management within their organizations, including staff groups, task forces, subordinates, direct and support groups and sometimes public officials, who continually present problems associated with organizational behaviour interventions. Ultimately, the use of specific managerial tools can contribute to boosting the administrative capacity to deal with turbulent organizational environments. Behavioural methods and quantitative techniques in organizations are closely related, and when applied in unison to problems solving, they yield optimum result (Foxley, 1980:9).

\section{Quantitative factors in decision making}

Some of the examples of quantitative factors in decision-making include investment appraisal, break-even analysis, market research, sales forecasting, critical path analysis, decision trees, chi square, correlation analysis, Regression analysis, Simulation, transportation analysis and t-test.

Quantitative factors give numerical basis for decision-making, namely reduces decisions merely to monetary value placed on different choices. Examples are forecasted sales figures for the next five years and the impact of redundancies on the long run income of the organisation due to this process. Such data affords 
only a fragment of the concept. There are other factors that should be taken into consideration, such as the effects of decisions on stakeholders and how they respond to a particular decision (Mallahi et al., 2005; Ehlers and Lazenby, 2007). For example, the unbundling and sale of Power Holding Company of Nigeria (PHCN) might make financial sense but the reaction of the staff and other stakeholders might make the move unsuccessful.

\section{Qualitative factors in decision making}

Qualitative factors include an analysis of the strengths, weaknesses, opportunities and threats (SWOT) (Ehlers and Lazenby, 2007). There is also the human resources management (HRM) analysis, which revolve around impact of management decision on firm's human resources in terms of motivation, morale, recruitment and retention (Prasad, 2004). The political, economic, social and technological (PEST) qualitative analysis is used to analyse external issues that might influence the decision-making process. Political could be the internal politics of a firm as well as the national and international political effect (Ehlers and Lazenby, 2007). The decision to site a series of wind turbines in a coastal area might be justified on financial grounds. But, the question is, what could be the reaction of the local community? Does the government policy support such planned development? Are there social impacts such as noise, pollution and damage to ecosystems? Such factors may make the difference between success and failure. Another area of focus is publicity and public image, long term survival/development issues and stakeholder analysis. Stakeholder analysis will necessarily consider the impacts of management's decision on stakeholder such as employees, Shareholders, local community, suppliers, government, consumers etc. (Kumar, 1993). Qualitative factors also take into consideration other issues that may influence the outcome of a decision. These could be wide ranging, such as the need to consider the impact of decisions making on human resources and their response to the decisions. A decision for example, to invest in a new production plant, could be considered not only in financial terms but by also applying other tools of decision-making to look at the wider issues.

Eventual decision may rest on the balance between the perceived effects of quantitative and qualitative criteria. If the longterm effect on the work force for example, was to reduce productivity or increase absence because of the impact on motivation and morale, the fact that a decision makes financial sense may be shelved. However, qualitative decision may be difficult to assess and measure. There is a need to distinguish between short-term and long-term effects, which may sometimes become subjective.

\section{Quantitative and qualitative methods}

Simply put, the terms 'qualitative' and 'quantitative' refers to the types of data generated in the research process (Holland, 2007, pp. 195-209). Quantitative research produces data in the form of numbers, while qualitative research tends to produce data that are stated in prose and textual forms. In order to produce different types of data, qualitative and quantitative research tend to employ different methods (Table 1).

\section{Mixed method approach}

Integrating qualitative and quantitative research methods lends depth and clarity to research results. This combination of approaches is necessary because of the wide range of data needed for organisational effectiveness. However, potential problems exist when attempting to combine such divergent research paradigms as one may end up not doing either type of research well. Therefore, this integrative research approach requires a research team with expertise in both types of methods (Table 2). Furthermore, using multiple approaches can also be time consuming, labour-intensive and expensive (Weinreich, 2006).

\section{Benefits of combining methods}

Using a combination of different methods, for example, qualitative and quantitative or soft/hard data is often the best choice. It allows for complementarity and triangulation, balancing limitations of each method. The challenge in mixing methods is to ensure that the conventions and limitations of each method are respected. For example, qualitative data should not be quantified and presented in percentages. In general, one should prefer flexible and iterative methodology rather than linear, and avoid elaborate and complex design (UNICEF, n.d).

\section{Complementary approach}

There is always a reason for adopting a particular approach. For instance, a survey might give a good measure of a situation, while focus group interviews are invaluable in the actual design of the survey (helping to explicate the right questions) and investigating the underlying causes as shown in Figure 1 (Unicef, n.d).

\section{Triangulation approach}

At times, there is a need to utilise multiple sources of data. The different types of triangulations are: data triangulation, which uses a variety of data sources in a study. For example, interviewing people in different occupations, status positions or belonging to different political parties on one or a series of issues. Investigator triangulation uses several different evaluators and social scientists. Method triangulation uses multiple methods to study a single problem or program, such as interviews, observations, questionnaires or using secondary sources. Theory triangulation uses multiple perspectives to interpret a single set of data. For example, observations of a drilling rig operation and interviews of primary stakeholders could be used rather than to measures both based on observations. This is more likely to provide data that is strong on different criteria as reflected in Figure 2 (UNICEF, n.d).

\section{Contingency approach}

The contingency approach recognizes that problems can be categorized in a number of different ways. Simon (1997:181) refers to problems on a continuum from well-structured to ill-structured. A well-structured problem has identifiable procedures for its resolution namely, the problem, when confronted, has a known methodology to resolve it. Mintzberg et al. (1983:246) have stated that an illdefined problem involves a task requiring decision processes that have not been encountered in quite the same form and for which no predetermined and explicit set of ordered responses exists.

The contingency approach led theorists to differentiate between programmed decisions to handle well-structured problems by providing routine and repetitive procedures and non-programmed decisions to handle a problem requiring a unique solution. Rules and policies predominate in programmed decisions thereby providing managers with a high degree of certainty about the appropriateness of the solution. In contrast, non-programmed decisions bring managers a high degree of uncertainty and therefore risk. The problem therefore requires both qualitative and quantitative methodologies to reduce the risk. When a manager 
Table 1. Quantitative versus qualitative methods.

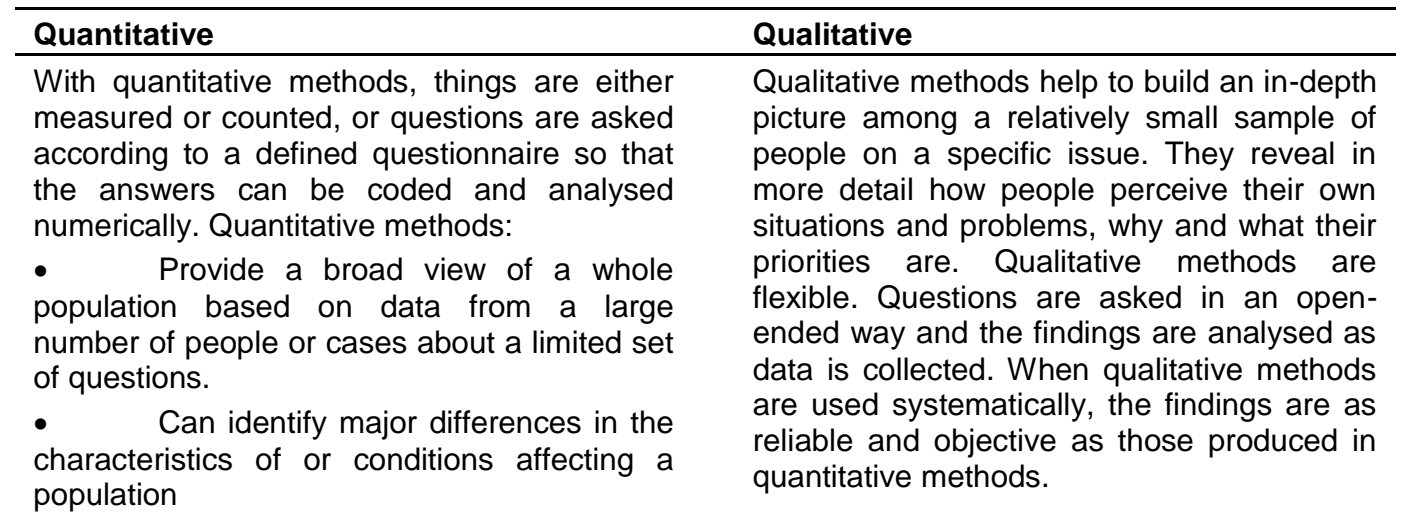

- Determine whether there is a statistical relationship between a problem and an apparent cause.

\section{Generalization/coverage}

Quantitative methods yield findings that are generalizable to the larger population based on data from large numbers of people or cases about a limited set of questions.

\section{Simplification of reality}

Quantitative methods tend to "simplify" the reality in the effort to provide hard, objective, numeric data.

\section{Objectivity}

Quantitative data are based on statistically sound methods of analysis and therefore can provide objective data that will allow generalizations.

\section{Standardized}

Quantitative data is collected through formalized processes and standardized tools. The research questions are formulated before the data gathering process. Instruments are developed, tested and applied following standardized procedures. The strict definition of research questions and tools guarantee the quality and comparability of the final results. However, they cannot be modified in the process of research. If ill-formulated, they could reflect the perceptions and preconceptions of the researchers and not the real needs of the beneficiaries.

\section{Exploration/depth}

Qualitative methods are intended for exploring issues. They do restrict data collection to a pre-set list of data. They allow more in-depth examination, but are less generalizable to a broader population.

\section{Complexity}

Qualitative data use informal approaches to capture differences and provide a more holistic approach to the reality.

\section{Interpretation}

Qualitative data are as a result of an interpretation process; they can offer invaluable in-depth analysis but, being at times "just a bit more than organized common sense"; qualitative techniques run the risk of superficiality, bias and errors. The data provided are clearly insufficient or nonrelevant where precise estimates or ratios are needed.

\section{Flexible}

Qualitative data is collected through much more flexible tools and techniques. Research guides and tools are reformulated during the process and new ones may be added, the research is an exploration. The evaluators/researchers must adapt, using flexibility to probe, while maintaining enough structure to allow systematic analysis of data. 
Table 1. Contd.

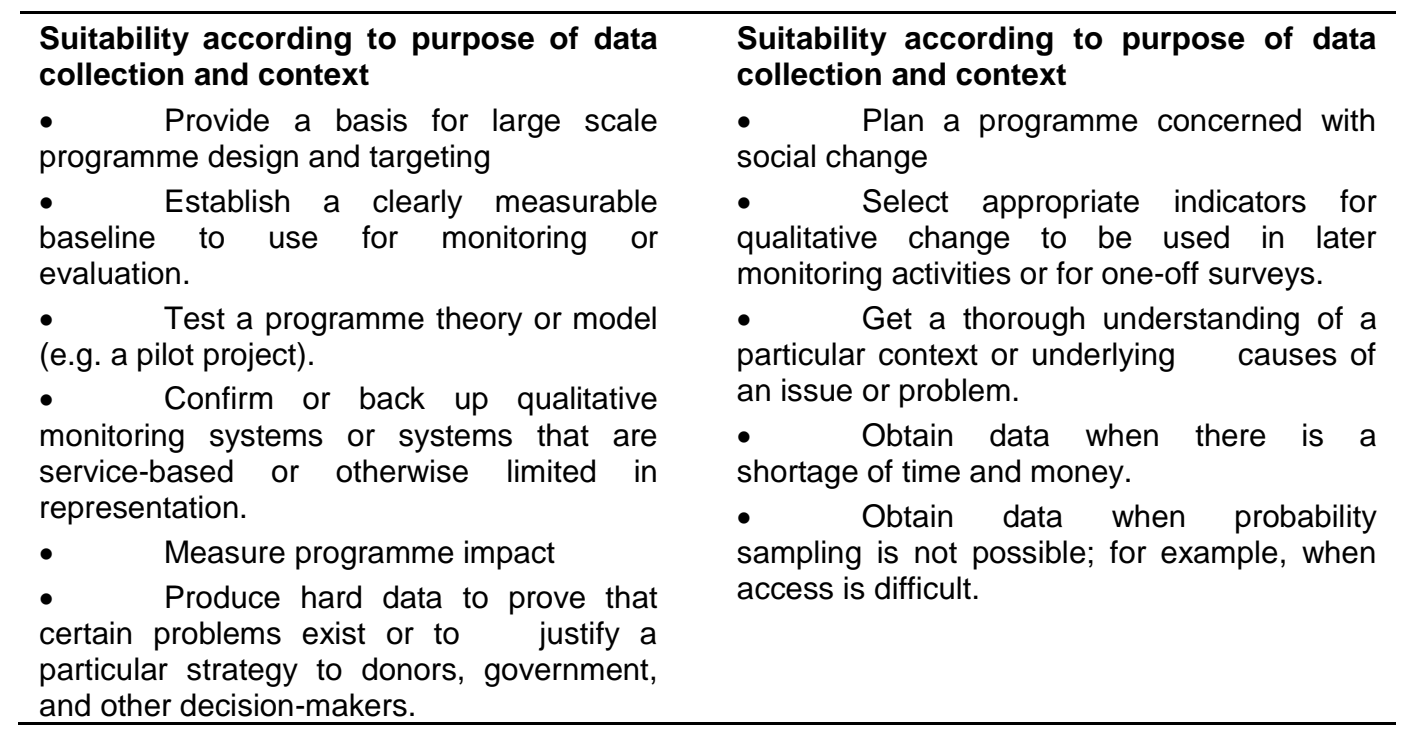

Source: Unicef (n.d).

Table 2. A typical case of mixed method approach.

In 1989, "an Indian scholar, Jodha, conducted a 20-years innovative study on the rate of poverty in two Indian villages. He utilised quantitative survey to collect data on quantitative indicators on household earnings and utilised these indicators to register the fortunes of the different households. The findings from the quantitative investigation were that $38 \%$ of the households sampled have become poorer during the period of 20 years. He further collected qualitative data from farmers who were considered to have become poorer. But the poor farmers' perceptions of change over the period of 20 years were phrased not in terms of falling income, but in terms of reduced reliance on patrons, reduced dependence on low-paid jobs, improved mobility and improved assets. Even though these farmers had become poorer in monetary terms, they saw that their quality of life has improved. Therefore, Jodha used qualitative analysis to examine why poor people felt they were better off. The reasons were that they had become more independence, more mobile and were no longer at the mercy of the village elites. This study is one of the best demonstrations of how qualitative and quantitative methods can be used to cross-validate data on the same indicators".

Source: (CIDA, 1996 cited in Unicef, n.d).

solves a problem in isolation the risk is higher than when a manager enrols others to assist in contributing to the solution. The risk may be reduced by a factor associated with the increased number of people who participate in the problem-solving. This is why some managers prefer to solve problems in a group or team (Bontis, 1999; Robin and Judge, 2009). The contingency approach has to deal with three questions. Firstly, when and under what conditions should a decision maker consider qualitative method as the appropriate technique? Secondly, when and under what conditions should a decision maker consider quantitative method as an appropriate technique? Thirdly, when and under what conditions should a decision maker consider mixed method as the appropriate technique?

One of the strengths of the contingency approach is that the strengths and weaknesses of qualitative, quantitative and mixed methods are recognized and all three approaches are considered to be important and needed, albeit in different circumstances.

\section{RESEARCH FINDINGS}

The application of both qualitative and quantitative tools is very essential in managerial decision-making for efficient and effective use of available resources for the growth and development of the organisation. If the two different management functional levels (executive and operative) in any organisation are unfamiliar with the various techniques, this might impact negatively on the decision-making process of the organisation and subsequently, its competitiveness. Therefore, it is pertinent for managers to enhance their decision-making competence through experiential and scientific knowledge acquisition. This will ensure a seamless decisionmaking process, effective communication mechanism and efficient use of resources by the organisation.

\section{Conclusion and Recommendations}

Effective decision-making depends on many factors. Consequently, there is need to have a dynamic decision- 


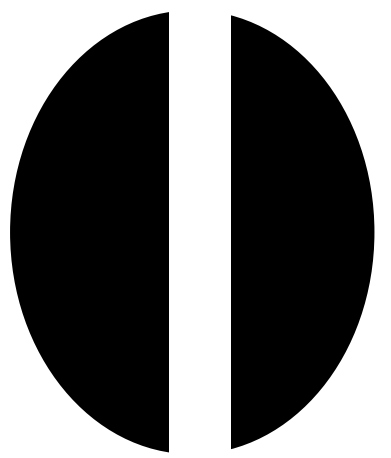

Figure 1. Complementary approach. Source: (UNICEF, n.d).

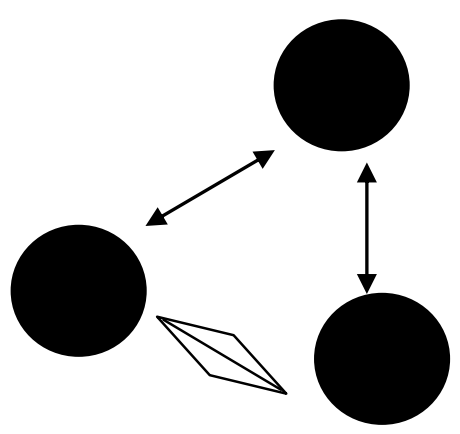

Figure 2. Triangulation approach. Source: (UNICEF, n.d).

making process that aligns with scientific decision-making procedures. Beside decision-makers experience, talent and quality, the use of suitable decision-making tools is also of significant importance. Therefore, managers should think about the three key contingency variables of environment, technology and people, before making a decision. Management requires the control of human resources, environment and material resources (technology) to achieve optimum objective. Management in the $21^{\text {st }}$ century has become more complex owing to globalization and technological development. Stakeholders are now more aware of their right and privileges, international laws are now superseding national/local laws and competition has now become intense. Therefore, effective and efficient decision-making by managers will guarantee a competitive edge for their organisations. This can only be achieved through the proper use of the appropriate decision-making tools. Because management is both an art and science, it has now become imperative that managers should equip themselves with decision-making aptitude.

Based on the foregoing, the following recommendations are worth pondering:
1. For an effective and efficient decision-making process, managers in various organizations need to not only have human relations skills but also, technical competencies.

2. Management team in organizations should inculcate the use of managerial science, statistics and quantitative approaches for planning, forecasting, cost analysis and evaluation, to ensure optimization of both human and material resources in their organizations.

3. Behavioural methods and quantitative techniques in organizations are closely related, and should be applied to problem-solving because they are essential productivity tools.

4. There should be an emphasis on the use of the different managerial techniques as part of the corporate strategic planning of organisations within a global and highly competitive context.

\section{REFERENCES}

Agrawal S, Subramanian SK, Kapoor S (2010). Operations ResearchContemporary Role in Managerial Decision Making. Int. J. Res. Rev. Appl. Sci. 3(2).

Anderson D, Sweeney D, Williams T (1994). An introduction to Management Science: Quantitative Approaches to Decision Making, Mason, USA: South Western Publishing Co.

Babbie E, Mouton J, Vorster P, Prozesky B (2001). The Practice Of Social Research, Cape Town: Oxford University Press.

Birnbaum MH (1998). Measurement, Judgment and Decision Making, Handbook of Perception and Cognition, California: 2nd Edition, Academy Press.

Bontis N (1999). Managing Organisational Knowledge by diagnosing intellectual capital: Framing and advancing the state of the field, Int. J. Technol. Manag. 18(5/6/7/8):433-462.

Cainta LD (2010). "Extent of Use of Qualitative and Quantitative Management Techniques in Administrative and Academic DecisionMaking Among Elementary and High School Principals/Head Teachers and Teachers-in-Charge in Zamboanga Del Norte School Divisions in Region ix", E-international Scientific Research Journal, ISSN: 2094-1749 Vol. 2 issue: 3.

Dunn WN (1994). Public Policy Analysis: An introduction, New Jersey: Prentice Hall.

Ehlers T, Lazenby K (2007). Strategic Management: Southern African concept and cases. Pretoria: Van Schaik Publishers.

Foxley C (1980). Determinants of Managerial Effectiveness, New Directions for Student Services, Vol.9.

Gibson FP, Fichman M, Plaut DC (1997). Learning in Dynamic Decision Tasks: Computational Model and Empirical Evidence. Organ Behav Hum Decis Process. 71(1).

Holland J (2007). Emotions and Research. Int. J. Social Res. Methodol. Theory Practice 10(3).

Kumar D (1993). Principles of management, Meerut: Kedar Nath Ram Nath and Co.

Mallahi K, Frynas JG, Finlay P (2005). Global Strategic Management, New York: Oxford University Press.

Mann D (1976). Policy Decision-Making in Education, New York: Teachers College Press.

Mintzberg H (1983). Power In and Around Organizations. New Jersey: Prentice-Hall.

Nisbett RE, Ross L (1980). Human Inference: Strategies and Shortcomings of Social Judgment, New York: Prentice-Hall.

Prasad LM (2004). Principles and practices of management, New Delhi: Sultan Chand.

Robbin SP, Judge TA (2009). Organizational Behavior, New Jersey: Pearson Prentice Hall.

Simon HA (1997). Administrative Behavior: A study of decision-making processes in administrative organizations New York: Free Press. 
Ukpere WI (2010). Capitalist globalisation in limbo, Germany: Lambert Academic Publishers.

Unicef (n.d) Quantitative and qualitative methods: Compared and Mixed [Online] available: www.ceecis.org/remf/Service3/unicef_e...,

Quantitative and Qualitative Methods, Compared and Mixed.

Weinreich NK (2006). Integrating quantitative and qualitative methods in social marketing research. [Online] available: http://www.socialmarketing.com/research.html
Valero CA (1997). Applications of Qualitative and Quantitative Techniques of Management in Administrative/Academic DecisionMaking in Institutions of Higher Education in Virginia, Dissertation submitted to the Faculty of the Virginia Polytechnic Institute and State University. 